\title{
Ionosphere-plasmasphere response to geomagnetic storms studied with the RMI-Dourbes comprehensive database
}

\author{
Jean-Claude Jodogne and Stanimir M. Stankov \\ Royal Meteorological Institute of Belgium, Brussels, Belgium
}

\begin{abstract}
Presented is a review of the ionospheric storm research carried out at the Royal Meteorological Institute (RMI) of Belgium. The studies are based on the opportunities offered by the long-term measurements and the accumulated comprehensive database managed by the RMI Geophysics Centre at Dourbes $\left(4.6^{\circ} \mathrm{E}, 50.1^{\circ} \mathrm{N}\right)$. Reported are case studies of major storms, and also results in developing forecasting and density reconstruction methods.
\end{abstract}

Key words ionospheric storms - synthetic geomagnetic index - electron profile reconstruction

\section{Introduction}

he ionospheric storm, defined as the set of large perturbations in the geomagnetic field and the ionosphere-plasmasphere system characteristics induced by solar flares and coronal mass ejections, is still a challenging subject of investigation. Observations of the ionosphereplasmasphere system response to storms have been well documented for several decades. Nevertheless, many questions remain unanswered and many early studies are now being questioned and improved by new discoveries. Recently, particular importance has been attribuited to studies of «space weather» (all geospace

Mailing address: Dr. Stanimir M. Stankov, Royal Meteorological Institute, Av. Circulaire 3, B-1180 Brussels, Belgium; e-mail: sstankov@oma.be phenomenae caused by the radiation and atomic particles emitted by the Sun and other stars).

Traditionally, the geomagnetic storm effects have been investigated by means of vertical radio-sounding measurement techniques (ionosondes) providing long series of data for the ionised atmospheric layers. Later, with advances in satellite technology, in situ observations of the plasma composition and behaviour have helped the research. Most recently, measurements of the Total Electron Content (TEC), both ground- and space-based, contributed significantly to the knowledge of the storms' global manifestation. In addition to the above methods, numerical modelling approaches allow the combination of various observations, better coupling with theoretical investigations, and spreading the information on essential processes and parameters over areas which are not directly observed.

The purpose of this paper is to present the ionospheric storm research carried out at the Royal Meteorological Institute (RMI) of Belgium. The studies are based on the opportunities offered by the long-term measurements and the accumulated comprehensive database managed by the RMI Geophysics Centre at Dourbes 
$\left(4.6^{\circ} \mathrm{E}, 50.1^{\circ} \mathrm{N}\right)$. Reported are case studies of two major storms in view of some important topics of interest, and preliminary results in developing new forecasting and electron density reconstruction methods.

\section{RMI Dourbes Geophysics Centre: history and observations}

The RMI Geophysics Centre at Dourbes is a complex observational site (fig. 1) consisting of several observatories - ionosphere sounding, atmospheric, geomagnetic, cosmic rays, TEC, etc. - all connected with optical-fibre communication lines. A fast link allows communication with the RMI in Brussels, the Royal Observatory of Belgium (ROB) and the Belgian Institute for Space Aeronomy (ISA). Some information is shared and available via the world wide web (WWW). First measurements at Dourbes started more than half a century ago and a vast amount of data have been accumulated during the years.

\subsection{Vertical ionospheric sounding}

The ionospheric soundings are carried out by a digital sounder (DGS-256) developed by the University of Massachusetts Lowell and featuring the operational characteristics given in table I. The DGS-256 ionosonde automatically calculates the electron density profile assuming a model valey and outputs the coefficients of a Chebyshev polynomials expansion. It is very important because it provides an opportunity for comparison of the ionosonde TEC (computed using ionosonde measurements) with the GPS TEC (GPS-based observations of TEC).

\subsection{GPS-based total electron content}

Some of the major advantages of using GPS to derive TEC are: the use of high frequencies (so that ionospheric absorption and geomagnetic field effects on the radio signal are small), electron content evaluated up to a very high altitude (20000 km, providing the plasmasphere con-

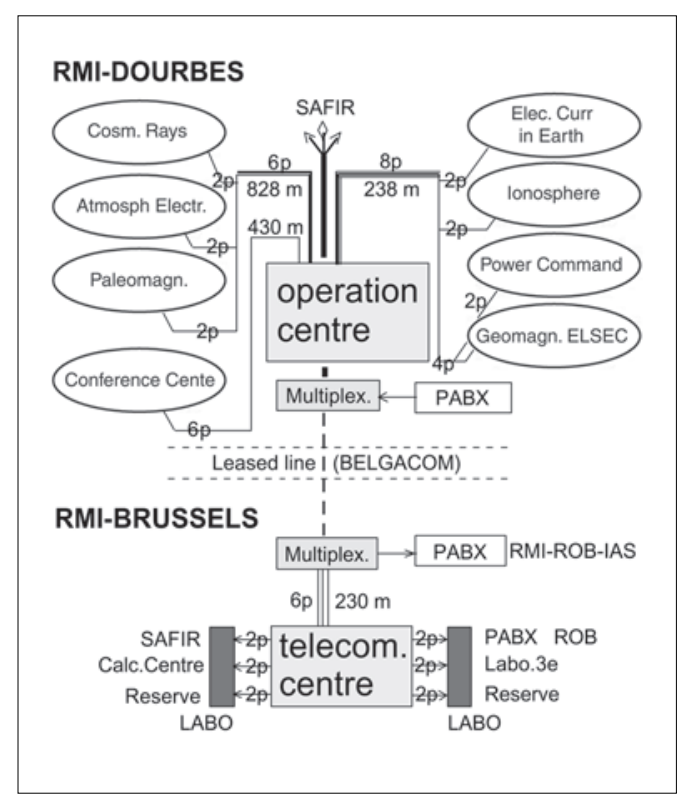

Fig. 1. The measurement and communication network of the Royal Meteorological Institute of Belgium. SAFIR - Thunderstorm alert system using radio interferometry. A $2 p$ connection consists of two cables with two optic fibres in each cable.

tribution to the content), operational global coverage (e.g., using the International GPS geodetic network), cost efficient observations (continuous signals and commercially available receivers).

At the RMI-Dourbes, a GPS receiver is collocated with the digital ionospheric sounder. Using the GPS signals on two coherent carrier frequencies $\left(L_{1} / L_{2}=1575.42 / 1227.6 \mathrm{MHz}\right)$, the TEC computation procedure (Warnant, 1997, $1998)$ is based on the "geometry-free» combinations of GPS code $\left(P_{p, G F}^{i}\right)$ and phase $\left(F_{p, G F}^{i}\right)$ measurements

$P_{p, G F}^{i}=P_{p, L_{1}}^{i}-P_{p, L_{2}}^{i}, \quad F_{p, G F}^{i}=F_{p, L_{1}}^{i}-\left(f_{L_{1}} / f_{L_{2}}\right) F_{p, L_{2}}^{i}$

where $P_{p}^{i}$ is the code measurement made by receiver $p$ on $i^{- \text {th }}$ satellite, $F_{p}^{i}$ is the carrier phase measurement made by receiver $p$ on the $i^{- \text {th }}$ 
Table I. The Dourbes (DB049) digital ionosonde - operational parameters and settings (after Reinisch, 1996).

\begin{tabular}{ccc}
\hline \hline Operational parameter & Range & DB049 ionogram settings \\
\hline Frequency range & $0.5-30[\mathrm{MHz}]$ & $1-16$ \\
Frequency scale & Linear or logarithmic & Linear \\
Frequency steps & $5,10,25,50,100,200[\mathrm{kHz}]$ & $100[\mathrm{kHz}]$ \\
Range resolution & $2.5,5.0,10.0[\mathrm{~km}]$ & $5.0[\mathrm{~km}]$ \\
Number of range pixels & 128,256 & 128 \\
Range start & Selectable & $60[\mathrm{~km}]$ \\
Pulse repetition range & $50,100,200\left[\mathrm{~s}^{-1}\right]$ & $100\left[\mathrm{~s}^{-1}\right]$ \\
Pulse width & $66,133[\mu \mathrm{s}]$ & $66[\mu \mathrm{s}]$ \\
Transmitter RF power & $\leq 10[\mathrm{~kW}]$ & $5[\mathrm{~kW}]$ \\
Duration of ionogram & Selectable & $4[\mathrm{~min}]$ \\
Phase code & 12 bit linear & \\
Digitization & $0.25[\mathrm{~dB}]$ & \\
Amplitude resolution & $1.4^{\circ}$ & \\
Phase resolution & Interpulse pseudo-random biphase coding & $4[\mathrm{~Hz}]$ \\
Doppler resolution & O/X & \\
Wave polarization & Video and paper & \\
Data display & Disk, cartridge & \\
Data storage & &
\end{tabular}

satellite, and $f_{L_{1}}, f_{L_{2}}$ - the frequencies on the $L_{1}, L_{2}$ carriers respectively. Rewritten as functions of TEC, the above equations read

$$
\begin{gathered}
P_{p, G F}^{i}=-1.05 \times 10^{-17} \mathrm{TEC}_{p}^{i}+\left(D_{p}-D^{i}\right) \\
F_{p, G F}^{i}=-5.52 \times 10^{-17} \mathrm{TEC}_{p}^{i}+N_{p, G F}^{i}
\end{gathered}
$$

where $N_{p}^{i}$ is the phase ambiguity, $\mathrm{TEC}_{p}^{i}$ is the slant electron content (along the $i^{\text {th }}$ satellite raypath) in TECU, $D^{i}, D_{p}$ are the $i^{- \text {th }}$ satellite and $p^{- \text {th }}$ receiver differential group delays. The ambiguity is eliminated by the following combination of «geometry-free» code and phase measurements:

$$
P_{p, G F}^{i}-\lambda_{L_{1}} F_{p, G F}^{i}=\left(D_{p}-D^{i}\right)-\lambda_{L_{1}} N_{p, G F}^{i}
$$

where $\lambda_{L_{1}}$ is the $L_{1}$ carrier wavelength. The formula requires the estimation of the receiver and satellite group delays, which are obtained from (2.2) after modelling TEC by means of a simple polynomial depending on latitude and local time. The conversion to vertical TEC is performed by assuming that the ionosphere is a layer of infinitesimal thickness located at a «mean ionospheric» height of $350 \mathrm{~km}$ and using a simple cosine function of the zenith angle at the «ionospheric point» (the raypath's point at the mean ionospheric height). Finally, the TEC value is calculated from (2.3). To obtain a TEC value, representative of the ionosphere above a given observing station, the following is applied: first, selected are all TEC values within a latitude difference of $1.5^{\circ}$ from the latitude of the observing station, and second, computed is the mean of these TEC values over 15 min periods. Measurements have been conducted in Dourbes on a regular basis since 1994 and a large TEC database has been created for the best part of the current solar-activity cycle. 


\subsection{Geomagnetic measurements}

From the beginning, the goal of the designers was the best measurements of the geomagnetic induction. The observatory building was erected without any ferromagnetic material even for the external paint. Double-core fluxgate magnetometers are used for measurements (Primdahl, 1979; Jankowski and Sucksdorff, 1996). These magnetometers are robust, have reliable electronics, and are capable of recording not only the field variations but its full strength as well. Absolute declination, inclination and induction values are manually determined with Theodolite, Diflux and Overhauser protons magnetometer respectively. An optical pumping Cesium magnetometer provides data each second. The precision level is $0.1 \mathrm{nT}$ for the induction and $0.001^{\circ}$ for the angles. Data are sent each hour to the METEOSAT satellite in the INTERMAGNET format. The large data bank on magnetic support started in 1957. A team uses also cryogenic magnetometers to make paleo- and archeo-magnetic studies. The horizontal component is deduced from measurements of the total field $(B)$ and inclination $(I)$, and their trigonometric relation $H=B \cdot \cos I$.

Local magnetic observations can be very helpful in many aspects. One particular advantage, concerning the present study, is the opportunity for near real-time detection of geomagnetic storm onset. Such detection can be performed by identifying the SSC using observations of the geomagnetic field's horizontal component variations. The apparent shape of $\mathrm{SSC}(\mathrm{H})$ is not a simple increase but rather manifests some variety. Morphological SSC studies (Matsushita, 1967) reveal that the shape of $\operatorname{SSC}(\mathrm{H})$ depends on local time and latitude, and can be sorted in the following major types: i) a small negative impulse preceding the main positive impulse; ii) a main positive impulse alone; iii) an increase (lasting up to about six minutes) followed by a decrease to a level lower than the initial pre-SSC level. However, the SSC detection is not always easy, particularly when performed on a real-time basis. A similar abrupt disturbance without succeeding large changes, called «sudden impulse», can be mistaken for a SSC.

\subsection{Cosmic rays}

The interplanetary space is continuously traversed by very energetic nuclear particles called cosmic rays. Their origin is not definitely determined - some certainly originate from the Sun and other stars, but others are associated with various energetic processes in the galaxy. Cosmic rays consist mostly of protons $(\sim 94 \%)$ and helium nuclei $(\sim 5.5 \%)$, with few nuclei of heavier elements (galactic component of the cosmic rays). The particles have a broad energy range, from less than $1 \mathrm{GeV}\left(10^{9} \mathrm{eV}\right)$ to more than $10^{11} \mathrm{GeV}\left(10^{20} \mathrm{eV}\right)$. In interplanetary space, the cosmic ray flux is in the order of 0.6 particles $\mathrm{cm}^{-2} \mathrm{~s}^{-1}$, the energy flux is $5 \mathrm{GeV} \mathrm{cm} \mathrm{cm}^{-1}$, and the space density - approximately $0.8 \times 10^{-10}$ particles $\mathrm{cm}^{-3}$ (Akasofu and Chapman, 1972). The high energy of the galactic cosmic rays means that they also have a very high penetrating power. Near the Earth, their motion is influenced by the geomagnetic field. When penetrating deep into the atmosphere, the cosmic rays collide with the atmospheric constituents and the results are different according to the energy input. Protons with energies of about $0.1 \mathrm{GeV}$ isotropically scatter the products of the collisions, such as protons, $\alpha$-particles and neutrons. The paths of these products appear as radial lines from the collision point, forming a «star». If the energy of the protons is of higher order (several $\mathrm{GeV}$ ), then $\pi$ mesons are also produced, which are scattered forward and their paths appear as a «shower». When the energy of the incident protons is more than $10^{3} \mathrm{GeV}$, the products are scattered into a narrow cone called a «jet». The protons produced collide with new atmospheric particles generating similar reactions. Thus, the newly-generated rays/particles permeate the atmosphere and can even reach ground level. Eleven-year cycle variation of the cosmic rays is detected, affecting the lower-energy cosmic rays much more than the higher-energy ones.

The interplanetary shocks and their drivers (the fast coronal mass ejections) play an important role in the modulation of the cosmic rays. Since the earliest observations of the cosmic rays (Forbush, 1938) it has been recognized that transient decreases in the cosmic ray intensity (Forbush decreases) occur at the times of sudden 
commencement geomagnetic storms and that the cosmic ray intensity varies regularly and inversely to the sunspot cycle, with the ray flux most pronouncedly decreased at high solar activity. Therefore, the Forbush decreases (produced by large-scale solar-wind disturbances) can be successfully used for investigating ionospheric storms and related phenomena (Barnden, 1973; Barouch and Burlaga, 1975; Zhang and Burlaga, 1988; Cane et al., 1993, 1994; Shadrina et al., 2002; Gonzalez et al., 2002).

At the RMI-Dourbes, a 9NM-64 neutrons monitor provides measurements of the secondary neutron component of the cosmic rays on the ground. After pressure correction this component faithfully follows the primary cosmic rays intensity. A large data bank of the hourly intensities has been existing since 1967.

\section{Case studies of storms}

In a broad sense, the «ionospheric storm» is defined as the set of disturbances that appear in the ionosphere immediately following a geomagnetic storm commencement (Hargreaves, 1992). The mechanisms accounting for the storm effects are composition changes, neutral winds, electric fields, etc. The individual case studies of geomagnetic storms and effects are considered as powerful instruments deepening our understanding of the inter-related processes of energy and momentum transfer, and of the kinetic, chemical, and electrodynamic coupling in the chain of solar-terrestrial relations. The main reason for this is the fact that during ionospheric storms the ionospheric processes are intensified and a phenomenon normally occurring over a long period is observed during a relatively short time period. Two major topics were investigated: the neutral winds effect on the ionosphere and the electrodynamic mechanism.

The global manifestation of the neutral wind effect starts at high latitudes where the perturbations in the interplanetary medium and the magnetosphere yield increased energetic particle precipitation, convection electric fields and associated Joule heating. The Joule heating raises the temperature of the thermosphere at auroral latitudes resulting in enhanced equatorward winds and travelling ionospheric disturbances in all local time sectors. On the night-side the poleto-equator wind field is enhanced. On the dayside, the equatorwards wind counteracts (and often overpowers) the solar-driven poleward winds. As a result of the air drag, the day-time $F$-region experiences upward motion and an ion density increase. This contributes to the «positive phase» in the critical frequency and total electron content values, whose increase is usually observed on the first day of the storm.

Large-scale structures of the Earth's plasma environment are determined by electrodynamic processes of magnetospheric and solar wind origin. For example, the electrodynamic drift can redistribute plasma to regions of either high or low chemical loss. Moreover, the $\boldsymbol{E} \times \boldsymbol{B}$ effect of the electric fields mapped down the geomagnetic field lines during storms is instantaneous. Unanswered questions are: the exact interplay of processes during the positive phase, the degree to which magnetospheric convection effect can penetrate to midlatitudes, coupling of atmospheric regions and processes, etc. (Szuszczewicz et al., 1998; Namgaladze et al., 2000; Foerster and Jakowski, 2000).

Geomagnetic storms are predominantly investigated using magnetic, ionosonde, and GPSbased measurements, all available at the Dourbes Geophysics Centre. The geomagnetic activity characterisation is based on evaluation of the geomagnetic disturbances with two major types of indices in use - the $K$ and Dst indices (Menvielle and Berthelier, 1991). The ionosonde measurements are important not only with the critical frequency $\left(f_{0} F_{2}\right)$ measurements but also with the peak density $\left(N_{m} F_{2}\right)$, peak height $\left(h_{m} F_{2}\right)$, and propagation factor $M_{3000} F_{2}$ :

a) The $f_{0} F_{2}$ values respond quickly to the storm, and together with TEC measurements, they can provide a crucial information on the slab thick-ness.

b) The $N_{m} F_{2}$ values will be used for calculating the slab thickness $\tau$, where $\tau[\mathrm{km}]=806.405$ TEC $\left[10^{16} \mathrm{~m}^{-2}\right] / f_{0} F_{2}^{2}[\mathrm{MHz}]$. This parameter can provide information on the plasma uplifting processes, plasmasphere fluxes, etc.

c) The $h_{m} F_{2}$ will give more information on the profile and the $F_{2}$ layer response to the storm, particularly in connection to the uplifting process. 
The TEC measurements are used together with the ionosonde measurements. No storm studies seem possible nowadays without the TEC value, especially after the introduction of the GPS system providing opportunities for a global coverage.

\subsection{The storm on 10th January 1997}

As a first example, we present the study of the storm on 10th January 1997, which has been well documented on a global scale because of the pre-observed and announced large coronal mass ejections on 6th January 1997 (Jakowski et al., 1999; Mikhailov and Foerster, 1999). This storm is characterised by a pronounced positive response from both TEC and $f_{0} F_{2}$ parameters for example, the noon TEC values are more than $100 \%$ higher than the monthly median (fig. 2c). The basic storm features are summarised in table II. Several aspects of the ionospheric response can be investigated from Dourbes and it will be demonstrated on this particular storm.

The positive storm phase is generally accepted to be induced by the strong southward thermospheric winds. The most significant consequence is the plasma uplifting effect - the strong meridional winds push the $F_{2}$-layer plasma upward, leading to reduced $F_{2}$-layer peak density and increased $h_{m} F_{2}$ and TEC. This effect can be easily detected from measurements through the slab thickness shape parameter $\tau$; increasing slab thickness (e.g., rising TEC accompanied by constant or decreasing $f_{0} F_{2}$ ) indicates plasma uplifting. A clear demonstration of this process is detected in the 09:00-10:00 UT period when TEC is rising, $f_{0} F_{2}$ is almost unchanged, and $h_{m} F_{2}$ also increases (fig. 2c,d). The wind-induced uplifting takes place along the geomagnetic field lines, and is therefore most efficient near the $45^{\circ}$ geomagnetic inclination. Situated at $50.1^{\circ} \mathrm{N}$, the Dourbes Geophysics Centre provides an excellent database for investigating the above-mentioned effect.

Other storm effects, the plasma fluxes from the plasmasphere, are due to the compression of the geomagnetic field during the onset phase of the storm (Foerster and Jakowski, 2000) and/or inter-hemispheric flows (Menietti et al., 1988).

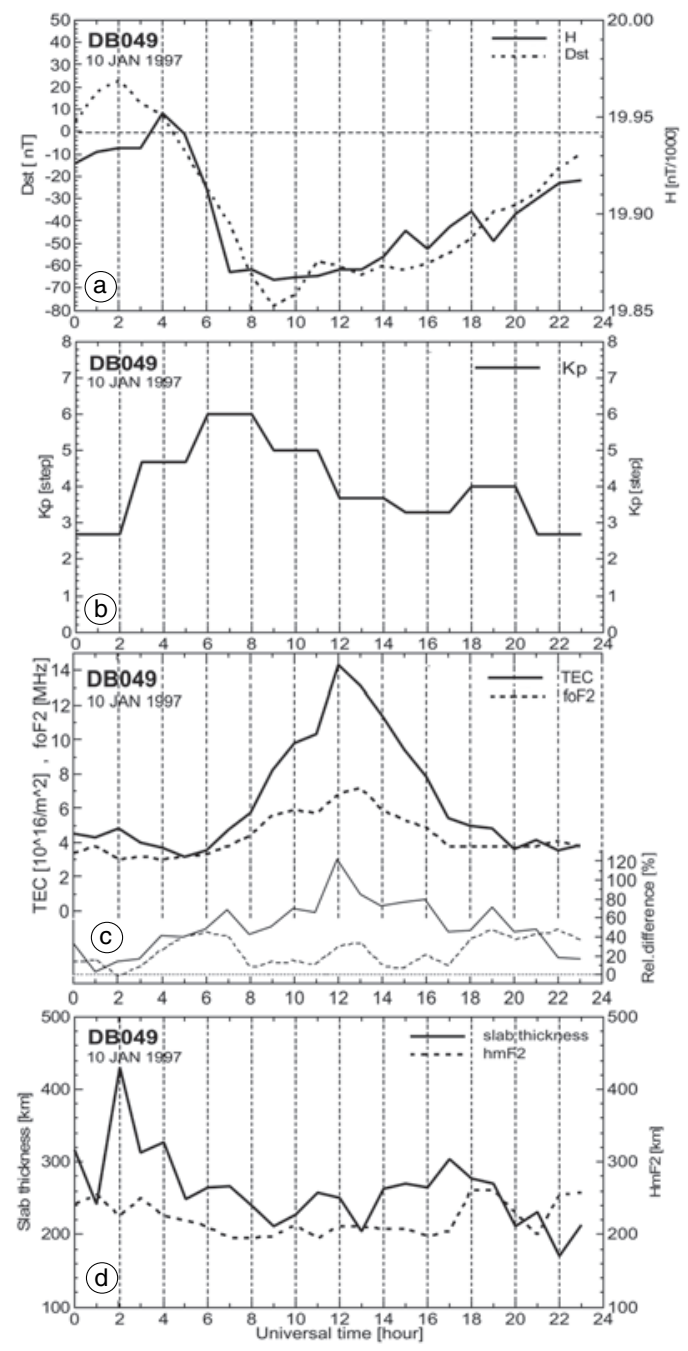

Fig. 2a-d. Ionosphere-plasmasphere response to the 10th January 1997 geomagnetic storm, as observed at the site of the Dourbes ionosonde station DB049 $\left(4.6^{\circ} \mathrm{E}, 50.1^{\circ} \mathrm{N}\right)$.

Such plasmaspheric fluxes can be easily detected: e.g., a high slab thickness value during nighttime is certainly an indication of an enhanced plasma influx from above, and this is exactly the situation observed near 02:00UT (fig. 2d).

The next effect of interest is associated with the generated convection electric field. The sharp 
Ionosphere-plasmasphere response to geomagnetic storms studied with the RMI-Dourbes comprehensive database

Table II. Summary of the 10th January 1997 storm characteristics.

\begin{tabular}{|c|c|c|}
\hline Feature & Value & Comments \\
\hline Storm onset (SSC) & 01:00 UT & 01:00 UT, 10/1/1997 \\
\hline$D s t(\min )$ & $-78 \mathrm{nT}$ & 09:00 UT, 10/1/1997 \\
\hline $\begin{array}{l}\text { Total storm period } \\
(\text { Dst } \leq-50 \mathrm{nT})\end{array}$ & $10 \mathrm{~h}$ & 08:00 UT (10/1/1997) - 17:00 UT (10/1/1997) \\
\hline $\begin{array}{l}\text { Initial plus main phase } \\
\quad(\mathrm{SSC} \rightarrow D s t(\mathrm{~min}))\end{array}$ & $8 \mathrm{~h}$ & 01:00 UT (10/1/1997) - 09:00 UT (10/1/1997) \\
\hline $\begin{array}{c}\text { Main phase } \\
(-50 \mathrm{nT} \rightarrow \text { Dst }(\min ))\end{array}$ & $1 \mathrm{~h}$ & 08:00 UT (10/1/1997) - 09:00 UT (10/1/1997) \\
\hline $\begin{array}{c}\text { Recovery phase } \\
(\text { Dst }(\min ) \rightarrow-50 \mathrm{nT})\end{array}$ & $9 \mathrm{~h}$ & 09:00 UT (10/1/1997) - 18:00 UT (10/1/1997) \\
\hline
\end{tabular}

decrease of the slab thickness after 02:00 UT shows the reaction to this field. There is no unique explanation for the decrease; a possible explanation is the occurrence of zonal disturbance electric fields. A westward electric field moves the plasma from higher to lower $L$-shells with smaller volumes. Thus, the plasma pressure in the flux tubes is increased, causing an enhanced plasma flux from the plasmasphere down to $F_{2}$ region altitudes. An eastward electric field results in the opposite effect of plasma decompression so that the plasmaspheric flux decreases (Mikhailov and Foerster, 1999).

The ionospheric storms can be much better investigated on a global scale. For the purpose, the RMI and ROB jointly upgrade the existing GPS TEC measurements to provide the TEC values at practically every point in the European region. The propagation velocity of the perturbation is one of the important storm characteristics that can be investigated in this way. Some authors (Hernandez and Roble, 1978; Proelss et al., 1991; Proelss, 1997; Jakowski et al., 1999; Foerster and Jakowski, 2000) estimate this velocity in the order of $400-900 \mathrm{~ms}^{-1}$. Theoretically, due to the reduced ion drag on the night side, the propagation should be much faster than on the day side. It is possible to estimate the time delayed ionospheric reaction using simultaneous GPS TEC and ionosonde data. For example, if we observe the exact time of the day-time TEC peak (fig. 2c) at various geomagnetic latitudes near $0^{\circ} \mathrm{E}$, we find that the peak is observed at $65^{\circ} \mathrm{N}$ in $11: 30 \mathrm{UT}$, at $50^{\circ} \mathrm{N}$ (Dourbes) in 12:30 UT, at $35^{\circ} \mathrm{N}$ in 13:00 UT. Thus, it obviously takes about $90 \mathrm{~min}$ for the plasma uplifting to move from $65^{\circ} \mathrm{N}$ to $35^{\circ} \mathrm{N}$, which corresponds to a wind velocity of approximately $600 \mathrm{~ms}^{-1}$. It is of crucial importance to have higher resolution data (more frequent measurements) during storm times. For example, if we work with hourly data, the above peak would be observed in 11:00, 12:00, 13:00 UT, hence the time delay would be 120 min resulting in a different wind velocity estimate. At the Dourbes Geophysics Centre we are able to provide $15 \mathrm{~min}$ sampling rate for GPS TEC and even better rate for the digital ionosonde. Thus, the TEC peak is observed at 12:30 UT which ensures better estimation of the propagation velocity.

\subsection{The storm on 15 th July 2000}

Another example is the geomagnetic storm observed in the period 15th-17th July 2000. The SSC is recorded at 14:35 UT and follows a disturbed period starting approximately $24 \mathrm{~h}$ earlier. It is a very intense storm (fig. 3a,b) showing a pronounced negative response in both the TEC 

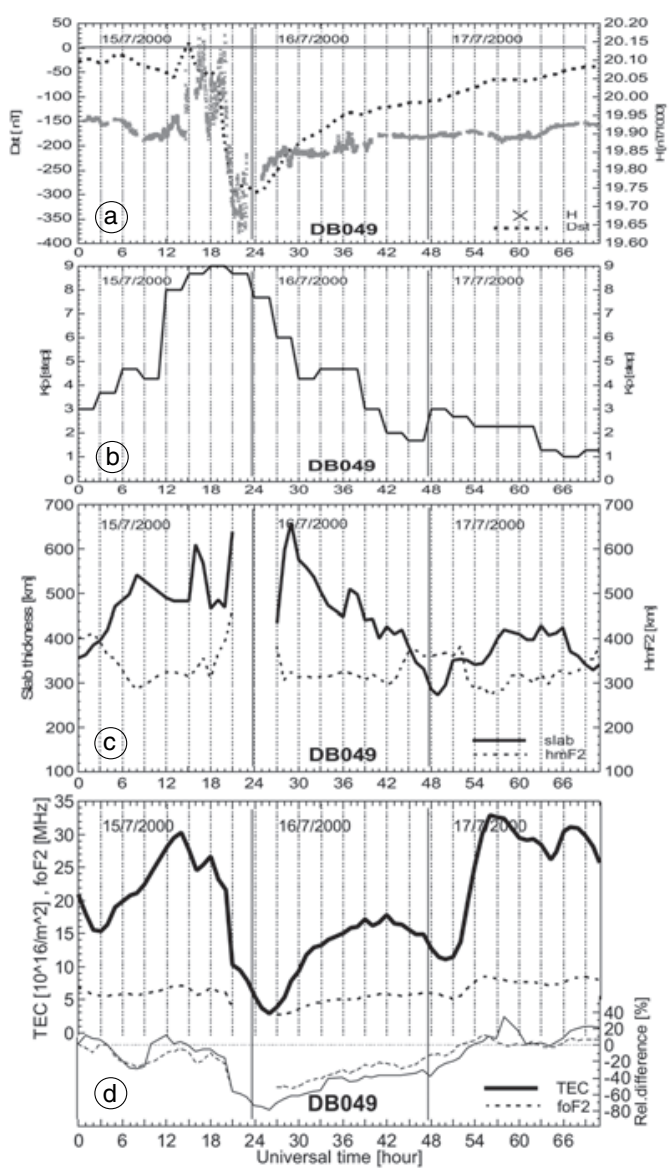

Fig. 3a-d. Ionosphere-plasmasphere response to the 15 th-17th July 2000 geomagnetic storm as observed at the site of the Dourbes ionosonde station DB049 $\left(4.6^{\circ} \mathrm{E}, 50.1^{\circ} \mathrm{N}\right)$.

and $f_{0} F_{2}$ values. Around 03:00 UT on 16th July 2000 , the relative differences increase to more than $-80 \%$ for TEC and $-50 \%$ for the critical frequency (fig. 3d). The most important storm characteristics are given in table III.

At high latitudes, the negative phase is attributed to the increased molecular concentrations of the thermosphere, enhancing the recombination processes and reducing the electron density. The standard explanation for a negative phase at middle and low latitudes (Szuszczewicz et al., 1998) is the enhanced equatorward wind system advecting the modified thermospheric composition to lower latitudes. This equatorward penetration is deeper at night-time, and theoretically, the corotation, coriolis forces, and zonal winds transport the modified thermospheric composition also to the day-time hemisphere and maintain the negative storm phase. Elements which complicate this simple picture involve: penetrating electric fields of magnetospheric origin, dynamo-driven fields, vertical and horizontal interactions between the wind system, thermospheric composition, ionospheric plasma, storm intensity, storm onset time (and associated local times in different longitude sectors), variations in pre-storm conditions, evolution of the controlling interplanetary-magnetospheric inputs, etc.

This storm is interesting in that it reveals another phenomenon, the so-called «ionogram $G$ condition». Under $G$ conditions, a measurement is influenced or impossible because the ionization density of the layer is too small to deduce the measurement value accurately. Such conditions occur during ionospheric disturbances associated with geomagnetic storms. Then, the electron density in the $F_{2}$ layer becomes equal to or lower than the electron density in the $F_{1}$ layer. In the result, $f_{0} F_{2}$ is expressed by the value of $f_{0} F_{1}$ with the descriptive letter $G$. This is exactly the case on 16th July 2002 (fig. $4 a$ ): $f_{0} F_{2}$ is equal to $f_{0} E$ during the day, except for a few hours (15:00-17:00 LT) in the afternoon.

However, it is important to separate the $G$ condition from two other confusing cases. The first case is when the $F_{2}$ trace disappears due to either interference or attenuation. The other case is when the trace cannot be recorded because of its extremely high virtual height exceeding the height range limit (descriptive letter $W$ ). This is obviously what happens from 21:00 UT on 15th July $2000\left(h^{\prime} F_{2}=520 \mathrm{~km}\right)$ to 03:00 UT on 16th July $2000\left(h^{\prime} F_{2}=513 \mathrm{~km}\right)$ when $h^{\prime} F_{2}$ is above these values and above the height range limit (fig. 4b).

In all of the above cases, the automatic ionogram scaling may fail to properly identify the $f_{0} F_{2}$ and $h_{m} F_{2}$ values, may not produce electron density profiles, or deliver profiles which can be quite different from the real ones. The 
Table III. Summary of the 15 th July - 17th July 2000 storm characteristics.

\begin{tabular}{ccc}
\hline \hline Feature & Value & Comments \\
\hline Storm onset (SSC) & $14: 35 \mathrm{UT}$ & $14: 35 \mathrm{UT}, 15 / 7 / 2000$ \\
\hline Dst $($ min $)$ & $-300 \mathrm{nT}$ & $21: 00 \mathrm{UT}, 15 / 7 / 2000$ \\
\hline $\begin{array}{c}\text { Total storm period } \\
(D s t \leq-50 \mathrm{nT})\end{array}$ & $49 \mathrm{~h}$ & $17: 00 \mathrm{UT}(15 / 7 / 2000)-18: 00 \mathrm{UT}(17 / 7 / 2000)$ \\
\hline $\begin{array}{c}\text { Initial plus main phase } \\
(\text { SSC } \rightarrow \text { Dst }(\text { min }))\end{array}$ & $6.5 \mathrm{~h}$ & $14: 35 \mathrm{UT}(15 / 7 / 2000)-18: 00 \mathrm{UT}(15 / 7 / 2000)$ \\
\hline $\begin{array}{c}\text { Main phase } \\
(-50 \mathrm{nT} \rightarrow D s t(\min ))\end{array}$ & $4 \mathrm{~h}$ & $17: 00 \mathrm{UT}(15 / 7 / 2000)-21: 00 \mathrm{UT}(15 / 7 / 2000)$ \\
\hline $\begin{array}{c}\text { Recovery phase } \\
(D s t(\text { min }) \rightarrow-50 \mathrm{nT})\end{array}$ & $45 \mathrm{~h}$ & $21: 00 \mathrm{UT}(15 / 7 / 2000)-18: 00 \mathrm{UT}(17 / 7 / 2000)$ \\
\hline
\end{tabular}

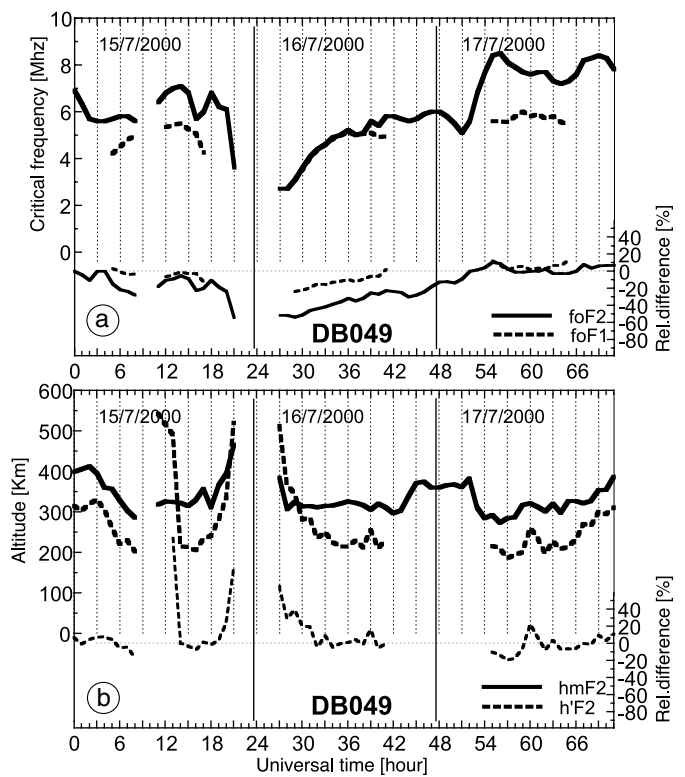

Fig. 4a,b. Ionosonde measurements during the 15 th 17 th July 2000 geomagnetic storm recorded at the Dourbes ionosonde station DB049 $\left(4.6^{\circ} \mathrm{E}, 50.1^{\circ} \mathrm{N}\right)$.

associated ITEC (ionosonde-based TEC) calculations, derived from such erratic profiles, can be very misleading. Concurrent GPS-based TEC measurements can be extremely useful. On the one hand, TEC measurements provide opportunities for identification and correction of ionosonde measurements under such $G / W$ conditions (fig. 3c,d). On the other hand, the TEC values can be used to reconstruct the electron profiles using the reconstruction method described in the following sections.

\section{Synthetic index of local response to the geomagnetic activity}

The response of a given ionosphere characteristic $F$ (like $f_{0} F_{2}, M_{3000} F_{2}$, or TEC) is better analysed through the relative deviation, $F_{\text {rel }}=$ $=\left(F_{\text {meas }}-F_{\text {med }}\right) / F_{\text {med }}$, of the actual observed characteristic from its median value, $F_{\text {med }}$. The response strongly depends, in a highly non-linear fashion, on geomagnetic indices such as the planetary indices $A_{p}$ and $K_{p}$ (Menvielle and Berthelier, 1991). For developing geomagneticallycorrelated short-term forecasting methods, a new synthetic index is required (Stankov et al., 2001; Muhtarov et al., 2002; and the references therein). This new synthetic index is actually a function showing the $F_{\text {rel }}$ dependance on the geomagnetic index ( $\operatorname{say} K_{p}$ ) used for the forecast. However, the new synthetic index (function) 
demonstrates strong seasonal and spatial variability and should be determined for each measurement site separately. At Dourbes, there are two types of measurements that can be used for the purpose - ionosonde $\left(f_{0} F_{2}\right)$ and GPS TEC measurements.

\subsection{The $f_{0} F_{2}$ response to geomagnetic activity}

The $f_{0} F_{2}$ response to geomagnetic activity was first deduced from $f_{0} F_{2}$ measurements carried out at Dourbes over the period from July 1957 to June 1989. It is calculated in the following manner. All values of the $f_{0} F_{2}$ relative deviations in a given month of the year are sorted according to the three-hour values of the planetary index $K_{p}$, which index is recorded in step values of 0.00 , $0.33,0.67,1.00,1.33, \ldots, 8.67$ and 9.00. Then, for each level of $K_{p}$ and each month, the basic statistics are calculated - average, standard deviation, data number, etc. Taking into account the expected seasonal variations in the ionospheric response to geomagnetic storms (FullerRowell et al., 2000), calculations were made and the results presented in fig. 5. The top four panels show the relative deviations of $f_{0} F_{2}$ for the months of January, April, July, and September; the contour plot at the bottom shows the detailed annual behaviour of the averages.

The first important observation was the distribution of the zero value of the $f_{0} F_{2}$ relative deviation $\left(f_{0} F_{2 \mathrm{rel}}=0\right)$, i.e. when $f_{0} F_{2 \text { meas }}=f_{0} F_{2 \mathrm{med}}$. This is the value representing the «average» magnetically quiet conditions. It is supported by the fact that the majority of the observations cluster at and around the median. It becomes obvious from the bottom contour plot that $F_{\text {rel }}=0$ is observed for $K_{p}=2.67$ except for the winter months when $F_{\text {rel }}^{p}$ varies between the higher values of 3.00 and 4.00 . Considering the definition of a quiet magnetic activity $\left(0<K_{p}<4\right)$, it follows that even within this interval a trend exists in the observations of $F_{\text {rel }}$ : a generally positive response for $K_{p}<2.67$ and negative response for $K_{p}>2.67$.

The second important fact is that the response of $f_{0} F_{2}$ under intense geomagnetic activity $\left(K_{p}>4\right)$ is generally negative, i.e. during storms the measurements are below their monthly medians. This negative response is particularly strong near the equinoxes (April and September) when the decrease reaches $25-30 \%$ during severe geomagnetic storms $\left(K_{p}>7\right)$. On the other hand, the maximum positive values of $F_{\text {rel }}$ are also observed during April and September for small values of $K_{p}$.

\subsection{The GPS TEC response to geomagnetic activity}

It is interesting to compare the critical frequency response with the response of the GPS TEC. The GPS TEC time-series data available at Dourbes (July 1994-October 2001) are not so long as the $f_{0} F_{2}$ series, and data scattering is rather large, but some important differences have already been detected. The TEC relative deviations $\left(\mathrm{TEC}_{\mathrm{rel}}\right)$ have been sorted in the same way as the $f_{0} F_{2}$ deviations and the results are provided in fig. 6. Again, the top four panels show the TEC relative deviations for the months of January, April, July, September, while the contour plot details the entire annual behaviour.

For the GPS-based TEC measurements, our calculations show that the TEC response is generally stronger and much more complex than the $f_{0} F_{2}$-based observations. First, the «quiet» behaviour, $\mathrm{TEC}_{\text {rel }}=0$, is detected at lower $K_{p}$ values of around 2.0, which is a sign for a stronger response to the geomagnetic activity. Second, it is obvious that, for quiet magnetic conditions $\left(K_{p}<4\right)$, the dependence of the relative TEC on $K_{p}^{p}$ is similar to that of $f_{0} F_{2}$. Third, for higher values of the $K_{p}$ index, the relative TEC stops decreasing and in many cases increases significantly particularly during winter months.

At this stage of investigation, the nature of this positive response is attributed mainly to the prolonged positive phase in the TEC storm-time behaviour. It is also clear that in November and December the increase of $\mathrm{TEC}_{\text {rel }}$ during storms can be as much as $20-25 \%$. There are indications that such an increase can be expected also during January and even February. Alternatively, pronounced decreases are observed in both April and September for values of $K_{p}>4$, although not as strong as in the $f_{0} F_{2}$ case. 

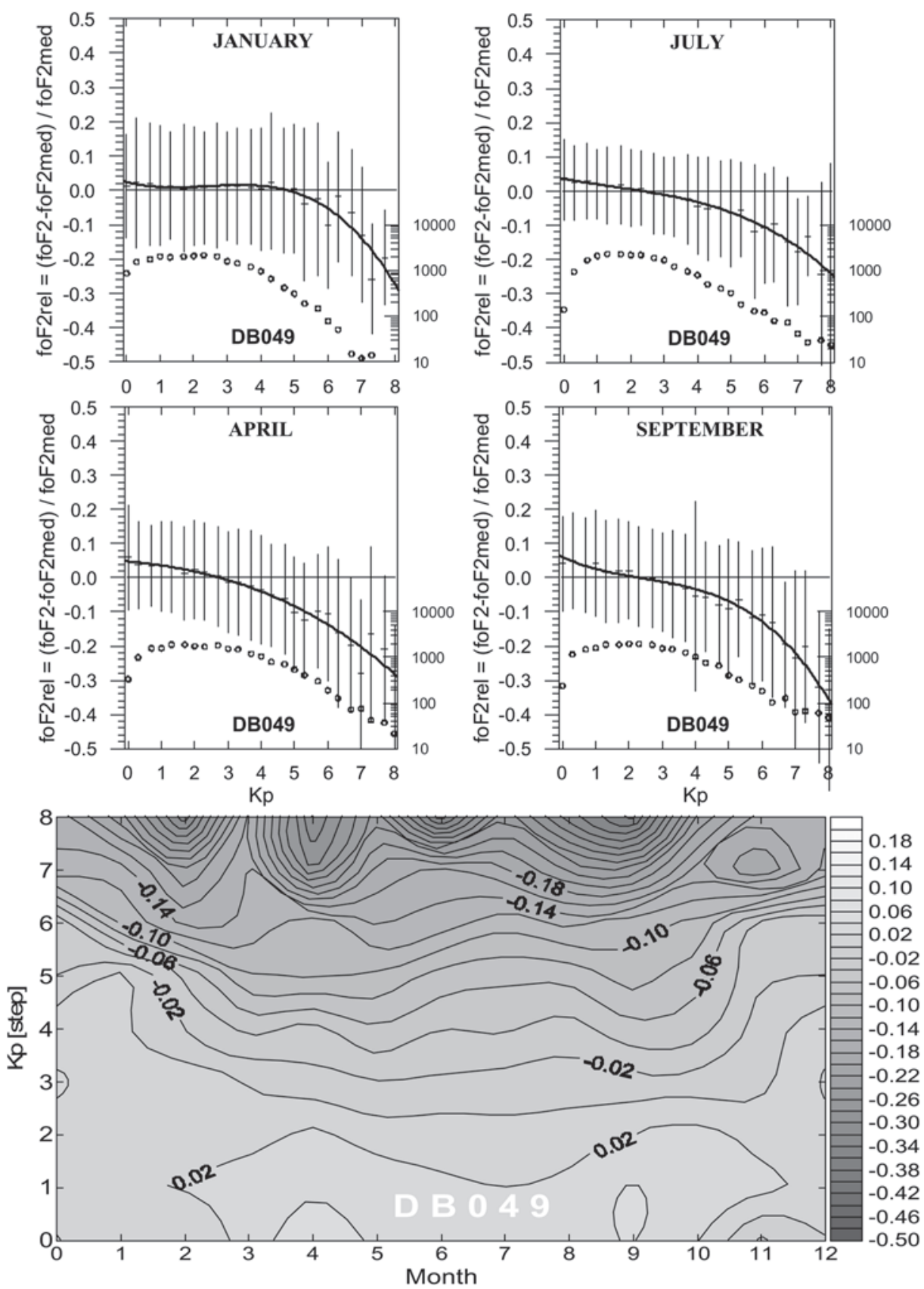

Fig. 5. The $f_{0} F_{2}$ relative deviations $\left(f_{0} F_{2 \text { rel }}\right)$ response to geomagnetic activity for the site of ionosonde station DB049 $\left(4.6^{\circ} \mathrm{E}, 50.1^{\circ} \mathrm{N}\right)$ based on data from the $1957-1989$ period. The average values of $f_{0} F_{\text {2rel }}$ (dashes) are approximated by $3^{\text {-rd }}$ degree polynomials (solid lines). The vertical bars represent the standard deviations (doubled), and circles represent the data number (scaled on the right-hand axis). 

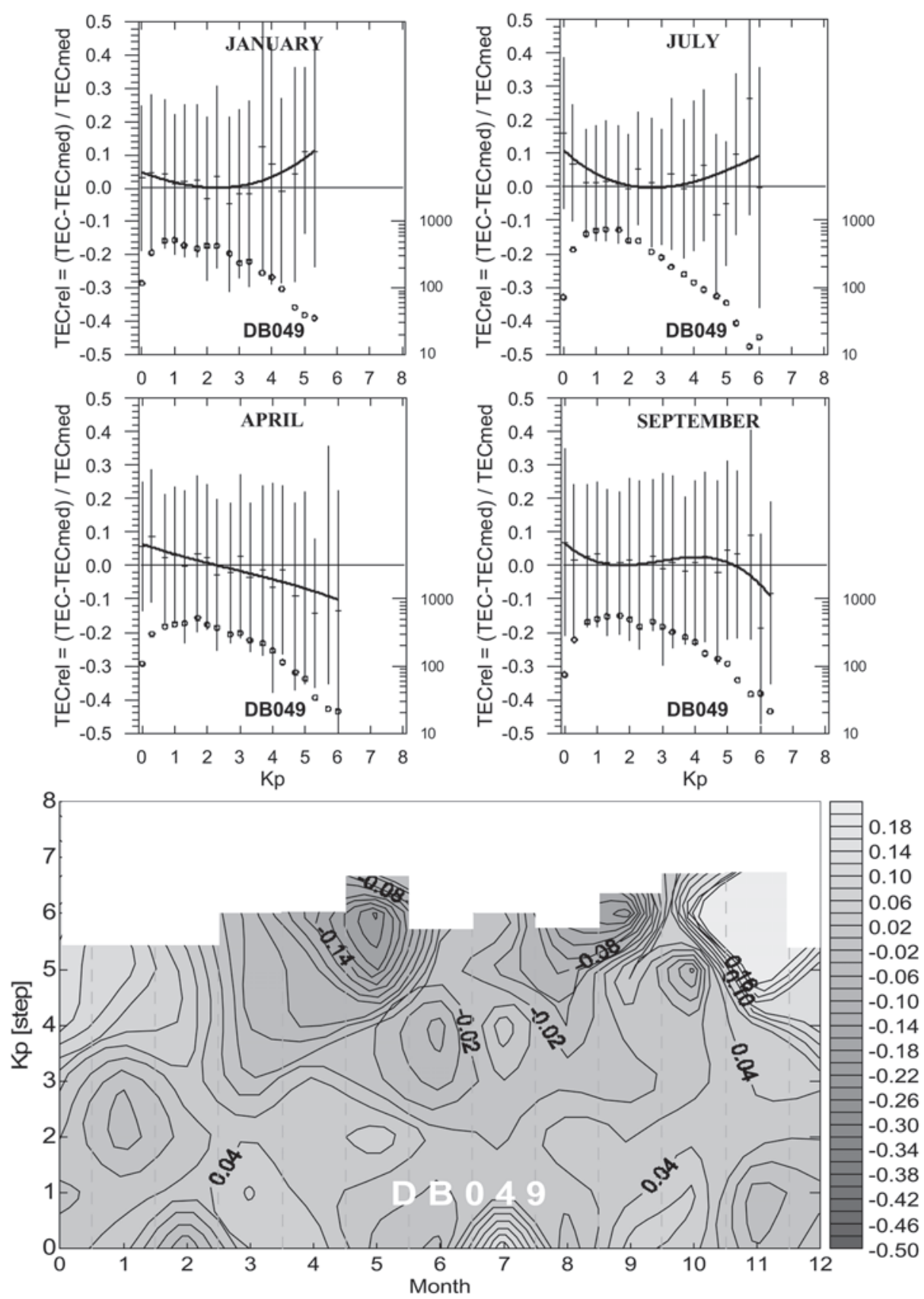

Fig. 6. The GPS TEC relative deviations $\left(\mathrm{TEC}_{\mathrm{rel}}\right)$ response to geomagnetic activity for the site of ionosonde station DB049 $\left(4.6^{\circ} \mathrm{E}, 50.1^{\circ} \mathrm{N}\right)$ based on data from the $1994-2001$ period. The average values of $\mathrm{TEC}_{\mathrm{rel}}$ (dashes) are approximated by $3^{\text {rd }}$ degree polynomials (solid lines). The vertical bars represent the standard deviations (doubled), and circles represent the data number (scaled on the right-hand axis). 
However, more GPS TEC measurement data and further analysis are required to better evaluate the TEC response to stronger geomagnetic activity, including the local time variation of the storm effects (Proelss, 1993). Statistical studies show (Davies, 1990) that, especially in middle latitudes, a geomagnetic storm follows different patterns depending on the local time of the
Sudden Storm Commencement (SSC). On the one hand, a geomagnetic storm in which the SSC occurs during daytime generally produces a TEC increase. On the other hand, the TEC during a storm in which the SSC occurs at night-time either goes directly to the negative stage, or increases for a short period during the afternoon of the following day. Nevertheless, the case

Table IV. Coefficients for the $3^{\text {-rd }}$ degree polynomial approximation of the average monthly response to geomagnetic activity; based on $f_{0} F_{2}$ (top table) and GPS TEC (bottom table) measurements at the site of the Dourbes ionosonde station DB049 $\left(4.6^{\circ} \mathrm{E}, 50.1^{\circ} \mathrm{N}\right)$.

\begin{tabular}{|c|c|c|c|c|}
\hline \multirow{2}{*}{$\frac{f_{0} F_{2}}{\text { Month }}$} & \multicolumn{4}{|c|}{ Degree } \\
\hline & 0 & 1 & 2 & 3 \\
\hline January & $2.4165 \times 10^{-2}$ & $-2.5847 \times 10^{-2}$ & $1.2986 \times 10^{-2}$ & $-1.8028 \times 10^{-3}$ \\
\hline February & $-1.0463 \times 10^{-3}$ & $2.4421 \times 10^{-2}$ & $-6.4418 \times 10^{-3}$ & $-1.4525 \times 10^{-4}$ \\
\hline March & $2.4913 \times 10^{-2}$ & $1.0363 \times 10^{-2}$ & $-8.2630 \times 10^{-3}$ & $3.6672 \times 10^{-4}$ \\
\hline April & $4.7779 \times 10^{-2}$ & $-9.7067 \times 10^{-3}$ & $-2.2601 \times 10^{-3}$ & $-2.1101 \times 10^{-4}$ \\
\hline May & $4.5731 \times 10^{-2}$ & $-1.6177 \times 10^{-2}$ & $-1.4128 \times 10^{-3}$ & $-1.8441 \times 10^{-4}$ \\
\hline June & $4.3341 \times 10^{-2}$ & $-3.1992 \times 10^{-2}$ & $7.2534 \times 10^{-3}$ & $-1.0285 \times 10^{-3}$ \\
\hline July & $3.6014 \times 10^{-2}$ & $-1.8669 \times 10^{-2}$ & $2.7797 \times 10^{-3}$ & $-5.9729 \times 10^{-4}$ \\
\hline August & $4.2705 \times 10^{-2}$ & $-2.9214 \times 10^{-2}$ & $7.4882 \times 10^{-3}$ & $-1.1622 \times 10^{-3}$ \\
\hline September & $6.0539 \times 10^{-2}$ & $-4.4463 \times 10^{-2}$ & $1.1422 \times 10^{-2}$ & $-1.5466 \times 10^{-3}$ \\
\hline October & $3.6506 \times 10^{-2}$ & $-2.6692 \times 10^{-2}$ & $7.4757 \times 10^{-3}$ & $-1.2045 \times 10^{-3}$ \\
\hline November & $-1.1878 \times 10^{-2}$ & $3.6587 \times 10^{-2}$ & $-1.0752 \times 10^{-2}$ & $4.7759 \times 10^{-4}$ \\
\hline December & $-5.0906 \times 10^{-3}$ & $2.2692 \times 10^{-2}$ & $-6.7083 \times 10^{-3}$ & $3.3266 \times 10^{-4}$ \\
\hline GPS TEC & \multicolumn{4}{|c|}{ Degree } \\
\hline Month & 0 & 1 & 2 & 3 \\
\hline January & $4.8198 \times 10^{-2}$ & $-2.2835 \times 10^{-2}$ & $-0.3204 \times 10^{-2}$ & $0.1971 \times 10^{-2}$ \\
\hline February & $-1.9767 \times 10^{-2}$ & $4.0903 \times 10^{-2}$ & $-1.4147 \times 10^{-2}$ & $0.1828 \times 10^{-2}$ \\
\hline March & $6.5163 \times 10^{-2}$ & $-7.4277 \times 10^{-2}$ & $2.5464 \times 10^{-2}$ & $-0.2299 \times 10^{-2}$ \\
\hline April & $3.8189 \times 10^{-2}$ & $0.9663 \times 10^{-2}$ & $-1.4048 \times 10^{-2}$ & $0.1399 \times 10^{-2}$ \\
\hline May & $1.7888 \times 10^{-2}$ & $-1.0004 \times 10^{-2}$ & $-0.3160 \times 10^{-2}$ & $0.0603 \times 10^{-2}$ \\
\hline June & $-3.4079 \times 10^{-2}$ & $8.8947 \times 10^{-2}$ & $-3.7321 \times 10^{-2}$ & $0.3786 \times 10^{-2}$ \\
\hline July & $7.1668 \times 10^{-2}$ & $-7.1640 \times 10^{-2}$ & $2.6913 \times 10^{-2}$ & $-0.2537 \times 10^{-2}$ \\
\hline August & $1.3113 \times 10^{-2}$ & $-1.9644 \times 10^{-2}$ & $1.1797 \times 10^{-2}$ & $-0.2037 \times 10^{-2}$ \\
\hline September & $4.8579 \times 10^{-2}$ & $-4.0954 \times 10^{-2}$ & $1.3645 \times 10^{-2}$ & $-0.1542 \times 10^{-2}$ \\
\hline October & $7.6576 \times 10^{-2}$ & $-1.5230 \times 10^{-1}$ & $6.0279 \times 10^{-2}$ & $-0.5746 \times 10^{-2}$ \\
\hline November & $-4.0179 \times 10^{-2}$ & $-1.4980 \times 10^{-2}$ & $2.1028 \times 10^{-2}$ & $-0.1998 \times 10^{-2}$ \\
\hline December & $-0.8146 \times 10^{-2}$ & $2.1755 \times 10^{-2}$ & $-0.2223 \times 10^{-2}$ & $0.0500 \times 10^{-2}$ \\
\hline
\end{tabular}


studies presented here reveal that there are storms which do not follow the common pattern proving the necessity of further investigations of such a complex issue.

\subsection{Synthetic index-approximation formulae for the local ionospheric response}

Considering the above analysis, it is possible to deduce simple analytical expressions of the $f_{0} F_{2}$ and TEC average response to the activity on a local basis. Such expressions can be used as a new synthetic index replacing the traditional $A$ and $K_{p}$ indices. The purpose of creating such index is the necessity to «linearize» the relationship between the relative deviations $\left(F_{\text {rel }}\right)$ of the ionospheric characteristic and the standard geomagnetic index $\left(e . g ., K_{p}\right)$, which is absolutely necessary for a reliable forecast based on the same characteristic. It is known that the mutual correlation between two random variables is highest when they are linearly dependent (Muhtarov et al., 2002).

New analytical expressions, using thirddegree polynomials, have been deduced for the synthetic index of local ionospheric response to geomagnetic activity. The polynomial coefficients are given in table IV for the site of the Dourbes ionosonde station.

\section{Reconstruction of electron density profiles}

Many ionosphere-plasmasphere processes, like the ionospheric storms and propagation delays in GNSS, can be estimated and corrected much more easily if the (vertical) electron density profile is available at a given location on a realtime basis. As the theoretical ionospheric models are not sufficiently good for the purpose, actual on-line measurements immediately available should be considered.

\subsection{Electron profiles deduced from ionosonde measurements}

The DGS-256 ionosonde automatically calculates the electron density profile assuming a model valey and outputs the coefficients of a Chebyshev polynomials expansion (Huang and Reinisch, 1996, 2001). The deduced electron density profile is very important as it provides opportunity to compare the TEC computed using ionosonde measurements with the GPS TEC available at the same site. The Ionosonde Total Electron Content (ITEC) is computed in the following manner (Warnant and Jodogne, 1998). The bottomside vertical electron density profile is obtained after standardized inversion of the $h^{\prime}(f)$ traces on vertical incidence ionograms with an accuracy of about $10 \mathrm{~km}$ as long as the profiles are monotonic. As the topside profile cannot be measured by the ground-based ionosonde, it is modelled with the $\beta$-Chapman function from the peak height up to the GPS satellite height of $20200 \mathrm{~km}$

$$
N_{T}(h)=N_{\max } \exp (1-z-\exp (-z))
$$

where $z=\left(h-h_{\max }\right) / H_{T}$ and $H_{T}$ is the top-side scale height. The topside scale height is calculated as the mean of the scale heights computed at three points of the bottom-side profile located at $88 \%, 90 \%$, and $92 \%$ of the $N_{\max }$. The ITEC is obtained after numerically integrating the electron profile. For the low solar activity period (1995-1996), the estimated mean and standard deviations of the (TEC-ITEC) distribution are 0.46 and $1.72\left[10^{16} \mathrm{~m}^{-2}\right]$, respectively.

\subsection{Electron profiles deduced from ionosonde and GPS TEC measurements}

A new technique has been recently developed (Stankov and Muhtarov, 2001, Stankov et al., 2002a) for retrieval of electron density profiles from concurrent GPS TEC and ionosonde data. The ionosonde measurements are used primarily for obtaining the bottom-side profile. Ionosonde data, together with simultaneously-measured TEC, are required for the topside electron profile determination. The unique determination of the top-side profile also depends on the availability of the $\mathrm{O}^{+}-\mathrm{H}^{+}$transition level (upper transition level, UTL) value. The following «reconstruction» formula is proposed for calculation of the top-side $\left(h>h_{m} F_{2}\right)$ electron density profile: 


$$
\begin{aligned}
N_{e}(h) & =N_{\mathrm{O}^{+}}\left(h_{m} F_{2}\right) \operatorname{sech}^{2}\left(\frac{h-h_{m} F_{2}}{2 \cdot H_{\mathrm{O}^{+}}}\right)+ \\
& +N_{\mathrm{H}^{+}}\left(h_{m} F_{2}\right) \operatorname{sech}^{2}\left(\frac{h-h_{m} F_{2}}{2 \cdot H_{\mathrm{H}^{+}}}\right)
\end{aligned}
$$

where $H_{\mathrm{O}^{+}}$and $H_{\mathrm{H}^{+}}$are the top-side $\mathrm{O}^{+}$and $\mathrm{H}^{+}$ scale heights, $N_{\mathrm{O}^{+}}\left(h_{m} F_{2}\right)$ and $N_{\mathrm{H}^{+}}\left(h_{m} F_{2}\right)$ are the $\mathrm{O}^{+}$ and $\mathrm{H}^{+}$densities at the $F_{2}$-layer peak height $\left(h_{m} F_{2}\right)$, and $\operatorname{sech}(h)=1 / \cosh (h), \cosh (h)=$ $=0.5(\exp (h)+\exp (-h))$. Several assumptions have been made: first, the height of the $\mathrm{O}^{+}$density maximum is equal to the height of the $\mathrm{H}^{+}$density maximum; second, the neutral particles and ions have the same scale height; third, the hydrogen and oxygen ion temperatures are equal. There are four unknown variables in the proposed formula: the ion densities $N_{\mathrm{O}^{+}}\left(h_{m} F_{2}\right)$ and $N_{\mathrm{H}^{+}}\left(h_{m} F_{2}\right)$, and the ion scale heights $H_{\mathrm{O}^{+}}$and $H_{\mathrm{H}^{+}}$. However, the number of unknown variables can be decreased by considering that $H_{\mathrm{H}^{+}} \approx 16 . H_{\mathrm{O}^{+}}$ following the definition of scale height. Therefore, the next system is constructed to determine the remaining three unknowns

$$
\begin{aligned}
& N_{\mathrm{O}^{+}}\left(h_{m} F_{2}\right)+N_{\mathrm{H}^{+}}\left(h_{m} F_{2}\right)=N_{m} F_{2} \\
& N_{\mathrm{O}^{+}}\left(h_{m} F_{2}\right) \operatorname{sech}^{2}\left(\frac{h_{t r}-h_{m} F_{2}}{2 \cdot H_{\mathrm{O}^{+}}}\right)= \\
= & N_{\mathrm{H}^{+}}\left(h_{m} F_{2}\right) \operatorname{sech}^{2}\left(\frac{h_{t r}-h_{m} F_{2}}{32 \cdot H_{\mathrm{O}^{+}}}\right) \\
\mathrm{TEC}_{t}= & 2 \cdot H_{\mathrm{O}^{+}} \cdot N_{\mathrm{O}^{+}}\left(h_{m} F_{2}\right)+32 \cdot H_{\mathrm{O}^{+}} \cdot N_{\mathrm{H}^{+}}\left(h_{m} F_{2}\right) .
\end{aligned}
$$

The first equation represents the principle of plasma quasi-neutrality and the fact that at the peak height, the only ion densities that really count are the oxygen and hydrogen ion densities. The second equation denotes the fact that the hydrogen and oxygen ion densities are equal at the $\mathrm{O}^{+}-\mathrm{H}^{+}$transition level $\left(h_{t r}\right)$; the level is obtained from a model based on satellite and rocket measurements (Stankov, 2002). The third equation is obtained after integrating the proposed $N_{e}(h)$ «reconstruction» formula (5.2) from $h_{m} F_{2}$ to infinity. The above system (5.3)(5.5) is solved numerically.

\subsection{Exemplary reconstruction results}

The reconstruction is demonstrated on actual GPS TEC and digital ionosonde data obtained at the RMI Geophysics Centre and using its measurements and communication network (fig. 1). The deduced electron density distribution is plotted in fig. 7 (top panel). The required input values of GPS TEC, $f_{0} F_{2}, f_{0} E, M_{3000} F_{2}$, UTL and $h_{m} F_{2}$ are given in the middle and bottom panels of fig. 7. The TEC and $f_{0} F_{2}$ show stronglycorrelated diurnal behaviour; both quantities increase sharply in the early morning, reach their absolute maximum just before noon, and then start gradually decreasing. Relatively high values are maintained throughout the afternoon, followed by a $10 \%$ increase in the early evening. After that, both TEC and $f_{0} F_{2}$ fall rapidly to their corresponding absolute minima observed at 02:00-03:00 LT. In the bottom panel, the $F_{2}$ peak-density and $\mathrm{O}^{+}-\mathrm{H}^{+}$ion transition level are also provided. The level, starting from $680 \mathrm{~km}$ at midnight, increases up to $1000 \mathrm{~km}$ at noon and then decreases in a symmetrical fashion during the second half of the day. The $h_{m} F_{2}$ has highest values at midnight (around $400 \mathrm{~km}$ ) and lowest values during day (varying between 300 and $330 \mathrm{~km}$ ). Notice the detailed density distribution above the $h_{m} F_{2}$. It is easy to detect the changes in the calculated topside scale height and resulting density distribution as they develop in time.

\subsection{A note on the operational reconstruction}

Recently, an operational procedure has been developed for real-time reconstruction of the vertical electron profile at a single ionosonde location (Stankov et al., 2002b).

In general, it is a stand-by procedure; its execution is triggered by either time control system 

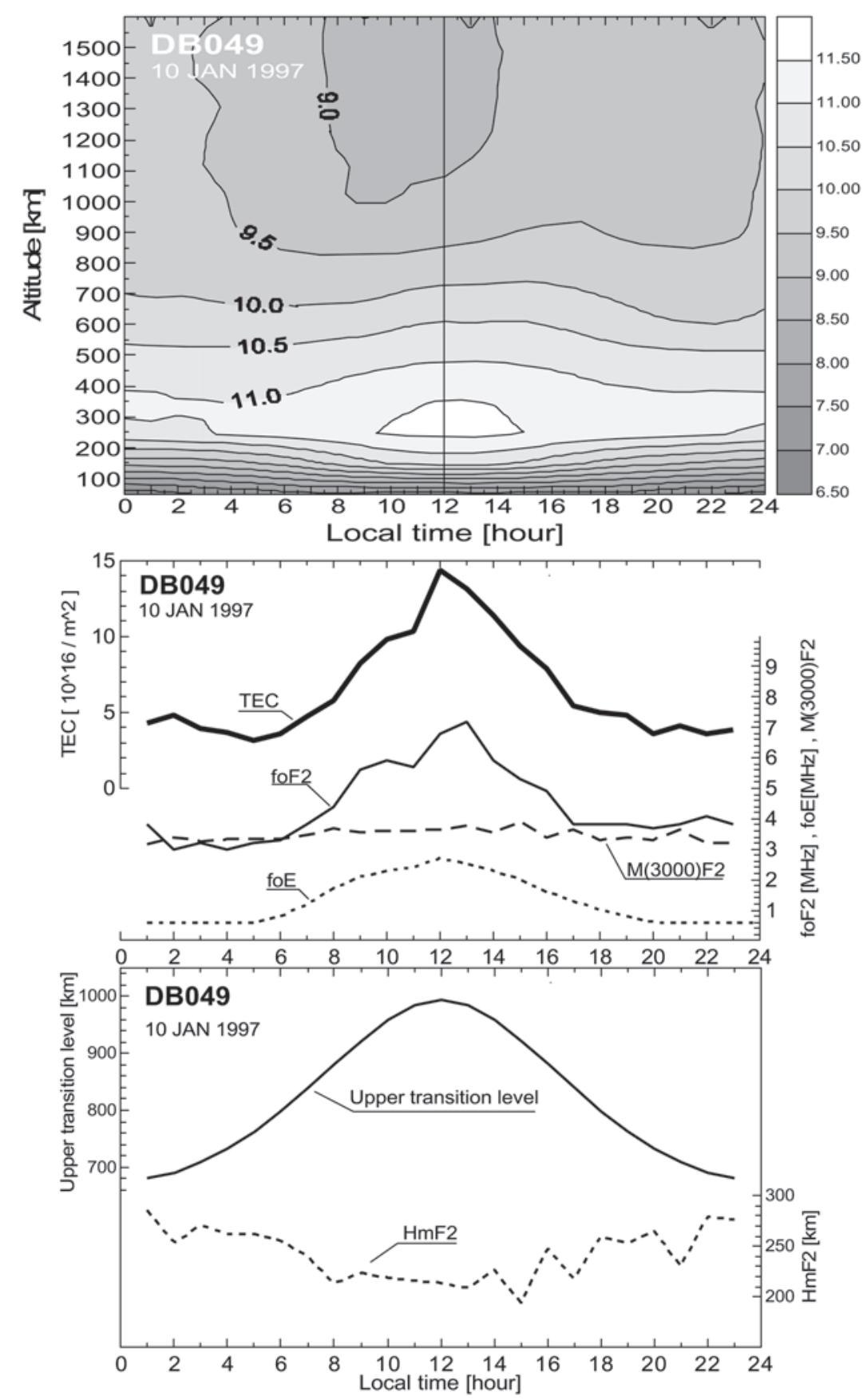

Fig. 7. Diurnal behaviour reconstruction: reconstructed vertical electron density (log scale, $\mathrm{m}^{-3}$ ) (top), actual GPS TEC and ionosonde measurements (middle), and model-based UTL and $H_{m} F_{2}$ (bottom). 
or new measurements. Thus, it relies heavily on regular discrete influx of (ionosonde and TEC) measurement data. Both types of observations should be synchronized, so representative data are obtained for given location and time. Highest flexibility, in terms of time resolution, is offered by the digital ionosonde - a new block of measurement data is available within a delay of about $5 \mathrm{~min}$. A longer delay is expected for receiving the GPS TEC value because the TEC derivation procedure (Warnant, 1997, 1998) requires time and a sufficient number of measurements to evaluate the hardware (receiver plus satellite) biases and detect possible irregularities (TID and scintillation effects). In practice, a TEC value can be obtained every $15 \mathrm{~min}$, which is sufficient for most applications.

Several distinct stages are observed in the operational reconstruction procedure: transmission of measurement data and retrieval of input parameters, construction of the bottom- and top- side electron profile, backup and display of results. The measurement data are transmitted using the File Transfer Protocol; the UTL values are provided by the empirical formulae (Kutiev et al., 1994) incorporated into the reconstruction software. If the TEC value is not available on time, it is possible to use the ionosonde-based TEC value. The final stage of the operational procedure is to store and display the results. As said before, the next round of calculations can be triggered by time control or the arrival of new measurements.

\section{Conclusions}

Presented was a review of some important ionospheric response studies carried out at the Dourbes Geophysics Centre of the Royal Meteorological Institute. The studies were carried out with the help of the local comprehensive database. Three major topics of importance to the ionospheric response investigations were covered case studies of storms, development of local geomagnetic activity indices for use in the shortterm forecasting, and reconstruction of the vertical electron density distribution. According to each of the above subjects, the following conclusions can be made:
Ionospheric storm studies:

- The storm studies are much more reliable and efficient if combined ionosonde and GPS TEC measurements are used.

- Higher resolution data (e.g., every $15 \mathrm{~min}$ ) are required for a better understanding of the dynamic ionospheric storm behaviour on a global scale.

- The local measurements of the horizontal geomagnetic field component can be used successfully as a reference for storm onset and subsequent main and recovery phases.

Short-term forecasting of $f_{0} F_{2}$ and TEC:

- The development of local synthetic geomagnetic activity indices is of crucial importance to the $f_{0} F_{2}$ and TEC short-term forecasting. Such indices are local storm-response characteristics of high precision.

- Differences are observed between the $f_{0} F_{2}$ and GPS TEC behaviour response to intense magnetic activity $\left(K_{p}>4\right)$, mainly with the detected positive response of TEC during winter in contrast with the all-negative $f_{0} F_{2}$ relative deviations.

\section{Electron profile reconstruction:}

- A recently-developed electron density reconstruction technique can be successfully utilized in investigating the local storm-time ionosphere development.

- A new operational procedure is being developed, which will provide the reconstructed electron density on a near real-time basis.

- An advantage of this method is its applicability on a global scale through the evergrowing GPS TEC and ionosonde measurements network.

In summary, the overall evaluation of the Dourbes measurement database proved a reliable research reference that will help to accomplish the above-stated goals.

\section{Acknowledgements}

This research was financially supported by the Belgian Federal Office for Scientific, Technical and Cultural Affairs and by the Royal Me- 
teorological Institute of Belgium. The authors thank Dr. R. Warnant for the useful discussions and GPS TEC data processing.

\section{REFERENCES}

AKASOFU, S.I. and S. ChAPMAN (1972): Solar-Terrestrial Physics (Oxford University Press, Oxford), pp. 901.

BARNDEN L.R. (1973): The large-scale magnetic field configuration associated with Forbush decrease, in Proceedings XIII International Cosmic Rays Conference, Denver, 2, 1277-1282.

BAROUCH, E. and L.F. BURLAGA (1975): Causes of Forbush decreases and other cosmic ray variations, J. Geophys. Res., 80, 449.

CANE, H.V., I.G. RICHARDSON and T.T. VON ROSENVINGEN (1993): Cosmic ray decreases and particle acceleration in 1978-1982 and the associated solar wind structures, J. Geophys. Res., 98 (A8), 13,295-13,302.

CANE, H.V., I.G. RICHARDSON, T.T. vON ROSENVINGEN and G. WIBBERENZ (1994): Cosmic ray decreases and shock structure: a multispacecraft study, J. Geophys. Res., 99 (A11), 21,429-21,441.

DAVIES, K. (1990): Ionospheric Radio (Peter Peregrinus Ltd., London), pp. 580.

FORBUSH, S.E. (1938): On the world-wide changes in cosmicray intensity, Phys. Rev., 54, 975.

FulLER-ROWELL, T.J., M.V. CODRESCU, H. RISHBETH, R.J. MoffetT and S. Quegan (2000): On the seasonal response of the thermosphere and ionosphere to geomagnetic storms, J. Geophys. Res., 101, 2343-2353.

FOERSTER, M. and N. JAKOWSKI (2000): Geomagnetic storm effects on the topside ionosphere and plasmasphere, Surv. Geophys., 21, 47-87.

GONZALEZ, W.D., B.T. TSURUTANI, R.P. LEPPING and R. SCHWEEN (2002): Interplanetary phenomena associated with very intense geomagnetic storms, J. Atmos. Sol. Terr. Phys., 64 (2), 173-181.

HARGREAVES, J.K. (1992): The Solar-Terrestrial Environment (Cambridge University Press, Cambridge), pp. 420.

HERNANDEZ, G. and R.G. ROBLE (1978): Observations of large-scale thermospheric waves during geomagnetic storms, J. Geophys. Res., 83, 5531-5538.

HuANG, X. and B. REINISCH (1996): Vertical electron density profiles from the Digisonde network, Adv. Space Res., 18 (6), 121-129.

HUANG, X. and B. ReINISCH (2001): Vertical total electron content from ionograms in real time, Radio Sci., 36, 335-342.

JAKOWSKI, N., S. SCHLUTER and E. SARDON (1999): Total electron content of the ionosphere during the geomagnetic storm on 10 January 1997, J. Atmos. Sol. Terr. Phys., 61, 299-307.

JANKOWSKI, J. and C. SUCKSDORFF (1996): IAGA Guide for Magnetic Measurements and Observatory Practice, IAGA, Warsaw, Poland.

Kutiev, I., S.M. STANKov and P. MARinov (1994): Analytical expression of $\mathrm{O}^{+}-\mathrm{H}^{+}$transition surface for use in IRI, Adv. Space Res., 17 (12), 135-138.

MatsushitA, S. (1967): Geomagnetic disturbances and storms, in Physics of the Geomagnetic Phenomena, edited by S. Matsushita and W.H. CAMPBELL (Academic Press, NewYork), 1153-1202.

MENIETTI, J.D., J.L. BURCH and D.L. GALLAGHER (1988): Statistical study of ion flows in the dayside and nightside plasmasphere, Planet. Space Sci., 36 (7), 693-702.

MENVIELLE, M. and A. BERTHELIER (1991): The $K$-derived planetary indices: description and availability, Rev. Geophys., 29 (3), 415-432.

MikHAILOV, A.V. and M. FoERSTER (1999): Some $F_{2}$-layer effects during the January 06-11, 1997 CEDAR storm period as observed with the Millstone Hill Incoherent Scatter Facility, J. Atmos. Sol. Terr. Phys., 61, 249-261.

Mutharov, P., I. Kutiev and L. CANDer (2002): Geomagnetically correlated autoregression model for short-term prediction of ionospheric parameters, Inverse Problems, 18, 49-65.

NAMGALADZE, A.A., M. FOERSTER and R.Y. YURIK (2000): Analysis of the positive ionospheric response to a moderate geomagnetic storm using a global numerical model, Ann. Geophysicae, 18, 461-477.

Primdhal, F. (1979): The Fluxgate Magnetometer, Geophysical Papers, R-55, Danish Meteorological Institute.

PROELSS, G.W. (1993): On explaining the local time variation of ionospheric storm effect, Ann. Geophysicae, 11 (1), $1-9$.

Proelss, G.W. (1997): Magnetic storm associated perturbations of the upper atmosphere, in Magnetic Storms, edited by B.T. TSURUTANI, W.D. GonZALEZ, Y. KAMIDE and J.K. ARBALLO, Geophys. Monogr. Ser, Am. Geophys. Un., Washington D.C., vol. 98, 227-241.

ProelsS, G.W., L.H. Brace, H.G. MAYR, G.R. CARIGNAN, T.L.KILLEEN and J.A. KLOBUCHAR (1991): Ionospheric storm effects at subauroral latitude: a case study, $J$. Geophys. Res., 96, 1275-1288.

REINISCH, B.W. (1996): Ionosonde, in The Upper Atmosphere - Data Analysis and Interpretation, edited by W. Dieminger, G.K. HARTMANN and R. LeITINGER, Springer, Berlin, 370-381.

SHADRINA, L.P., S.A. STARODUBTSEV and I.Y. PLOTINIKOV (2002): Geomagnetic storms and Forbush decreases during the passage of the Earth through the flanks of large-scale solar wind disturbances, Int. J. Geomagn. Aeron., 3 (1), 45-50.

STANKOV, S.M. (2002): Empirical modeling of ion transition levels based on satellite in situ measurements, $C$. R. Acad. Bulg. Sci., 55 (1), 35-40.

STANKOV, S.M. and P.M. MUHTAROV (2001): Reconstruction of the electron density profile from the total electron content using upper transition level and vertical incidence sounding measurements, C. R. Acad. Bulg. Sci., 54 (9), 45-48.

Stankov, S.M., I.S. KuTIEV, N. JAKOWSKI and S. HeISE (2002a): Electron density profiles deduced from GPS TEC, $\mathrm{O}^{+}-\mathrm{H}^{+}$transition height and ionosonde data, Acta Geod. Geophys. Hung., 37 (2-3), 171-181.

STANKOV, S.M., R. WARNANT and J.C. JODOGNE (2002b): A real-time operational procedure for GPS TEC - based 
reconstruction of the electron profile at a single ionosonde location, in Proceedings EGS XXVII General Assembly, 21-26 April 2002, Nice, France, Paper n. EGS02-A-05554.

Stankov, S.M., I.S. Kutiev, N. JAKOWSKI and A. WEHRENPFENNIG (2001): A new method for total electron content forecasting using global positioning system measurements, in Proceedings ESTEC Workshop on Space Weather, 17-19 December 2001, Noordwijk, The Netherlands.

SzUszCZEWICZ, E.P., M. LESTER, P. WiLKINSON, P. Blanchard, M. ABDU, R. HANBABA, K. IgARASHI, S PULINETS and B.M. REDDY (1998): A comparative study of global ionospheric responses to intense magnetic storm conditions, J. Geophys. Res., 103 (A6), 11,66511,684 .

WARNANT, R. (1997): Reliability of the TEC computed using
GPS measurements - the problem of hardware biases, Acta Geod. Geophys. Hung., 32 (3-4), 451-459.

WARNANT, R. (1998): Detection of irregularities in the total electron content using GPS measurements - application to a mid-latitude station, Acta Geod. Geophys. Hung., 33 (1), 121-128.

WARNANT, R. and J.C. JodOGNE (1998): A comparison between the TEC computed using GPS and ionosonde measurements, Acta Geod. Geophys. Hung., 33 (1), 147-153.

ZHANG, G. and L.F. BuRlaGA (1988): Magnetic clouds, geomagnetic disturbances, and cosmic ray decreases, J. Geophys. Res., 93, 2511.

(received April 10, 2002; accepted October 15, 2002) 